\title{
Vulnerable Learners' Experiences on Drug Abuse in Zimbabwean Rural Schools: A Literature Review Perspective
}

\author{
Munyaradzi Chidarikire, $\mathrm{PhD}^{1^{*}}$ Pinias Chikuvadze, $\mathrm{PhD}^{2}$ and Cecilia Muza ${ }^{3}$ \\ ${ }^{1}$ Bindura University Science Education, Zimbabwe \\ ${ }^{2}$ University of Free State, South Africa \\ ${ }^{3}$ Great Zimbabwe University, Zimbabwe \\ *Corresponding Mail: mchidas78@gmail.com
}

\begin{abstract}
In Zimbabwean rural schools, drug abuse is observed to be on the increase trend. It is in this context that this paper delved into experiences that are encountered by vulnerable learners abusing drug in rural schools. Accordingly, it targeted at how this social phobic has become entrenched in learners' way of being and the plausible antidotes to this drawback. In this regard, a framework derived from social constructionist and symbolic interactionist standpoints provided the lens through which the researchers perceived the issue under investigation. The researchers used literature review in the generation and analysis of learners' lived experiences with regards to the issue under study from different sources. The researchers used the narration of information from commissioned reports, newspaper articles and empirical findings. From consulted sources, the researchers noted that there is widespread drug abuse in most rural schools through the influence of the institution linked dynamics, age issues, life stress, peer group pressure, obtainability of ready money and ease of access to drugs. With respect to these findings, the researchers concluded that drug abuse by learners in rural schools in Zimbabwe was from literature perspective mostly due to multi-pronged influences. Hence the researchers recommended that key interested parties such as Government, Non- Governmental Organizations, parents, teachers and policymakers should consistently implement and monitor strategies such as peer counselling to mitigate the drug abuse among rural learners.
\end{abstract}

Keywords: Drug abuse, substance abuse, health, experience, rural schools, learners

\section{Introduction}

Globally, ancestors explored the properties of every plant, fruit, root and nut they found for various uses (Ngesu, Ndiku and Masese, 2008). As a result, human beings have used and abused certain substances since time immemorial (Masese, Nasongo and Ngesu, 2012). In almost all cultures, there has been the desire for man, consciously or unconsciously to escape from monotony, frustration and pains and to seek euphoria or a sense of well-being when taking part in different achievement tasks (Jiloha, 2009). Substances such as alcohol, marijuana and tobacco are included among the psychoactive substances (Awosusi and Adegboyega, 2013) that people may use for alleviation. The eventual use of these products would be partly determined by pharmacological effects, the nature, intensity and duration of strange or desirable new factors and partly by the particular group's pattern of living (Kombo, 2005).

Currently, drugs ranging from alcohol, cigarettes, marijuana, cocaine, heroin and many others are readily available to vulnerable rural learners and this has made many of them to be perpetrators of social vices in the society (Mhizha, 2010; Sambo, 2008). Owo (2012) states that all over the world the problem of alcohol and other drug abuse amongst school going teenagers is recognised as one of the greatest challenges of our time. Maithya, Muola and Mwinzi (2013) further state that over the past decades, the use of illicit drugs has spread at an unprecedented rate and has reached every part of the world. In Zimbabwe, $6.6 \%$ of the learners use alcohol at harmful or potentially harmful levels and 10.5\% use illicit drug (Dlamini and Makondo, 2017; 
Pelzer, 2009). The prevalence of psychoactive substances, according to Silva, Malbergier, Stemliuk and Andrade (2006), is increasing among learners of tertiary learning institutions and this has become a major public health and social concern. In this regard, the issue of drug and substance abuse in Zimbabwean rural schools can be linked to the period immediately soon after the attainment of independence (Chikoko, 2013).

The last decade has brought to attention an emerging problem of substance abuse in the Southern African region, including Zimbabwe. The current trend of substance abuse among adolescents on a period of transition from childhood to adulthood is a major national concern, as it is troubling and it has derogatory effects on adolescents such as physical, psychological and social changes or even death (Oliha, 2014; Yusuf, 2010).

Adolescence is the time of life when people are more interested in taking risks and testing the boundaries of the world outside as well as their own limits (Thun and Luiza da Costa de Silva, 2003). In this context, most learners in the rural education are usually within the adolescent age range of 14-19 years, a time of experimentation, exploration, curiosity and identity search (Olugbenga-Bello, Adebinpe and Abodurin, 2009). Today, no academic institution is immune to drug abuse as some learners are involved in use of illicit drugs and substances against institutions' set rules and regulations (Akanbi, Augustina, Theophilus, Muritala and Ajiboye, 2015; Omage, 2005). As a result, the drug abuse problem is affecting vulnerable rural learners. Studies done in Zimbabwe reflect that there is a culture of high drug abuse in the country. This is supported by the evidence in the study by Cooper (2009), who confirmed that a study on adolescent drug use assessed by teachers show that alcohol use was the most serious drug problem in Zimbabwe learning institutions.

Although most rural schools seem to have a code of conduct, at least on paper, research indicates that learner misbehaviour is rife in schools (Mestry and Khumalo 2012; Joubert and Serakwane 2009). For example, the study by Mutsvanga (2011, p. 65) indicated that "the substance use culture in Zimbabwe is fast spiralling out of control, sucking into its vortex, adolescents." Another study that substantiated drug abuse in Zimbabwe was done by Maseko, Ngwenya and Maunganidze (2014, p. 185), who found that "reports in Zimbabwe are consistent in telling remarkable expansion in students" interest in drugs and use of substances." From another angle, Oliha (2014) claimed that "many drug abuse behaviours are heavily tied to the peer culture, as children learn from and imitate the peers they like and admire." This resonates with literature, which states that there is a high level of drug abuse in rural schools. For example, the study done in rural areas by Cooper (2009) confirmed that $18.5 \%$ of learners use drugs. The problematic use of perilous drugs and substances amongst learners in Zimbabwe are immense than what has been so far articulated (Jakaza, Nyoni and Muzingili, 2018; UNICEF, 2006). It is in this context that the researchers derived the following main question: What are the factors influencing vulnerable learners to engage in drug abuse in Zimbabwean rural schools?

\section{Research Methodology}

This study adopted a desktop literature review as a methodology. Literature has been sourced from academic journals, books and news reports (DuBois and Miley, 2014; Fouché and Delport, 2005). This was chosen as a narrative inquiry to explore the journey from taking up to recovery from substance abuse amongst Zimbabwean rural learning institutions (Hancock, Windridge and Ockleford, 2010). The study sought to determine the social world in which learners live and why things are the way they are. With this insight, the researchers sought to understand the world of learners in rural tertiary education institutions. Thus, this allowed for the documentation of personal responses and views within the context a variety of rich data sources (Baxter and Jack, 2008; Blanche, Durrheim and Painter, 2006; Cresswell, 2009).

The researchers purposively sampled rich data sources (Creswell, 2009; McMillan and Schumacher, 2010). This ensured that the issue under investigation was not only looked at through a single lens, instead a variety of lenses such as commissioned reports, newspaper articles and empirical studies allowed for the phenomenon's multiplicity be implicit. This therefore called for an inductive approach to the analysis of responses that allowed for patterns, themes and categories to emerge (Cresswell, 2010). It was after this data solicitation that the researchers reflected on data gathered. Thereafter conclusions were advanced in line with demands of the main research question. 


\section{Discussion and findings}

This discussion was guided by a standpoint that looks at the issue under investigation through a holistic approach that identifies the influence as well as interaction of various fields of the biological, social, psychological and cultural environment of an individual (Zosel, et al., 2009). It is in this context that drug abuse (e.g. alcohol, cigarettes, marijuana, cocaine, heroin, hashish, illicit and/or prescription drugs) (Yusuf, 2010), becomes an addiction to most adolescents in schools. It is against this background that this discussion from the onset acknowledges that initiation into drug abuse as a complex issue is influenced by multiple factors. Hence, through reviewed literature, the researchers noted that in Zimbabwean rural schools, social and cultural factors to a larger extent have an influence on learners' involved in drug abuse (Jakaza, et al., 2018; Muwanzi and Mafumbate, 2018). The researchers therefore noted with a concern that there has been a dramatic upsurge in drug trafficking, intake and related drawbacks in rural schools (Geramian, Akhavan, Gharaat, Tehrani and Farajzadegan, 2012).

It is significant to bear in mind that rural schools receive learners with diverse backgrounds with the mission of inculcating competencies, which makes them functional in their societies. However, at times, these expectations are not met due to either institution based or learner based concerns such as the rapid social and cultural transitions that have created favourable conditions for disruptive drug abuse (Gutuza and Mapolisa, 2015; Mugabe and Maposa, 2013; Tesfaye, Derese and Hambisa, 2014). It is against this background that learners during their stay at home live a restricted life and this transition to rural schools exposes them to a more self-directed situation, which is mostly influenced by the existing environment (Makanjuola, Abiodun and Sajo, 2014; Olley, 2008). In this context, drug abuse in Zimbabwean rural schools is perceived to be on the rise, although published data is limited (Osman, Victor, Abdulmoneim, Mohammed, Abdalla, Ahmed, Ali and Mohammed, 2016).

With this background in mind, the researchers noted that drug abuse in rural schools is complex, with no single factor to explain the prevailing scenario in these institutions. It is against this background that the researchers therefore called for the integration of a number of factors so as to comprehend their complex interaction (Mathews and Benvenuti, 2014). Hence in this meticulous analysis of voluminous literature on drug abuse, the researchers realised that there was a gap in terms of strategies to deal with drug abuse in Zimbabwean schools (Chidarikire, 2019). In this context, the researchers used the Modified Stress Model as a lens through which factors influencing learners' drug abuse were observed (Ekpenyong, 2012). Thus through this model, factors influencing learners' involvement in drug abuse were identified. It is against this background that the researchers centred the discourse on factors that have an effect on initiation and perpetuation on drug abuse amongst learners in rural schools as seen below:

This section centres on exploring the preparedness of those charged with the managing of learners' affairs in the institution under investigation. The researchers took into cognisance the need to interrogate the level to which they are equipped with the relevant knowledge and skills to strategize, activate and impress upon the indispensable control of measures to fight against drug abuse amongst the learners. It is against this background that institutional administration needs to keep abreast of the changes in the society so as to be able to prepare learners to cope with emerging issues on drug abuse (United Nations, 1994). Therefore institutional administration should provide a direction and impetus for an effective fight against drug abuse amongst learners, with the view to achieve excellence in rural schools. This calls for an institutional administration that is in a position to provide favourable conditions for the learners' growth and development in all spheres of life. However, the researchers noted that this cannot be possible in circumstances where learners operate under harsh conditions, where they are not allowed to convey their grievances for an amicable resolution (The Standard Newspaper, 2019). Hence, this limited freedom on the side of the learners creates stress that can lead to drug abuse experiences.

In most rural schools, learners are adolescents, a transition stage from childhood to adulthood (Muwanzi, et al., 2018). Thus this is a considerable epoch of existence that is jam-packed with transformations and complications where they encounter 'storms, stress, turbulent and unstable' situations in a bid to discover and assert themselves in different spheres of life both within different schools and outside (Oketch, 1997). It is in this context that the researchers acknowledge that at 
this stage, youths tend to be trying out different things in life such as drug abuse. This experimentation results in risk-taking, which is a normal part of adolescent development (Sue, Sue and Sue, 2009). Adolescents think that engaging in risk-taking behaviour helps them to shape their identities, try out their new decision-making skills and gain peer acceptance and respect (Ponton, 2009).

The availability of cash to the youth as pocket money and travel allowances, especially if excessive can be redirected into purchasing of drugs. The money is usually not put into proper use and when opportunities arise, they team up with friends, taste drugs and eventually become drug addicts. According to a Daily Nation correspondent (The Daily Nation, 2012), students who get access to a lot of money are tempted to buy illegal drugs. Over involvement of some parents either in business or other activities outside the family also contributes to the abuse of drugs. Unlike in the past, socialization of the youth has been neglected. As a result, many children are left under the care of house helps because parents have to work. According to NACADA (Sunday Nation, 2008), there is a strong link between alcohol/drug abuse and the breakdown in family values. Blum (2017) asserts that peers have a high degree of influence only when parents have abdicated their traditional roles, hence actively involved parents may be able to limit the influence of peer groups on young people's ill attitudes. Kiru (2014) states that some youth from rich families' abuse drugs because they can afford them while some from poor families, due to frustrations, abuse cheap drugs such as alcohol. Ndirangu (2010) on the same also indicates that some parents are so much involved in search for money, fame and success to the point of leaving no time for children.

According to Merton and Nisbert (2016), people use illegal drugs because of their availability and promotion interests of those who are in a position to benefit financially from their sale. In Kisumu, The Big Issue (Standard, 2015) identified shops at the Kisumu bus stop and schools within the town centre as the best known dens of drugs taking. This, coupled with learners' curiosity to indulge in drug abuse in rural schools caught our attention. Hence there is need for us to focus on curiosity as having an influence on learners' involvement in drug abuse. Curiosity is one of Man's outstanding characteristics. It is not surprising then that many young persons will wish to try some drug in order to determine the effects for themselves. It is not surprising then that many young people will wish to try some drugs in order to determine their effects for themselves (WHO, 2018). According to Midigo (2012), it is not surprising to find students who are addicted to drugs while their initial reason for doing so was out of curiosity. He further conceded that young people are curious and like having fun. Therefore some take drugs in order to discover their effects.

A report in The Sunday Nation (2008) indicated that the environment in which children grow up plays a great role in shaping their character. The claim is that children socialized in the bar culture by their parents during entertainments will tend towards use of alcohol later in life (Manguvo, Whitney and Chareka. 2011). The report argues that this will impact negatively on the development of the children in the long run. The report further asserts that it is difficult for parents to sensitise their children about the dangers of alcohol consumption while they spend long hours imbibing in the company of the very people whose character they are expected to mould. Therefore, drug abuse among rural learners in Zimbabwe needs a collective effort among learners, parents, teachers as well as private and public sectors to fight drug abuse problem as it affects learners.

\section{Conclusion and Recommendations}

Drug abuse by learners in rural schools was influenced by various factors. Among them, are administration linked dynamics in dealing with drug abuse issues, learners' age, availability of cash, accessibility of drugs and the surrounding environment. With respect to these findings, the researchers concluded that drug abuse by learners in rural schools in Zimbabwe was from literature perspective mostly due to multi-pronged influences. Hence the researchers recommended that key interested parties such as Government, NonGovernmental Organisations, parents, teachers and policymakers should consistently implement and monitor strategies such as peer counselling to mitigate the drug abuse among rural learners. In addition, the researchers recommend that, stakeholders in rural schools should include learners and parents in the formulation of strategies to minimise the incidences of drugs abuse within schools and outside the school environments. Furthermore, there is need for a comprehensive and collective implementation of guidance and

\section{East African Journal of Education and Social Sciences (EAJESS) 2(2)80-86}


counselling in schools in relation to drug abuse among rural learners in Zimbabwe.

\section{Reference}

Akanbi, M.I., Augustina, G., Theophilus, A.B., Muritala, M. and Ajiboye, A.S. (2015). Impact of substance abuse on academic performance among adolescent students of colleges of education in Kwara State, Nigeria.Journal of education and practice, 6(28), 108-112.

Awosusi, A.O. and Adegboyega, J.A. (2013). Knowledge of health effects and substance use among students of tertiary institutions in Southwestern, Nigeria. Journal of Education and Practice, 4(23), 134-140.

Baxter, P and Jack, S. (2008) Qualitative case study methodology: Study design and implementation for novice researchers. The Qualitative Report. 13(4), 544-559.

Blanche, K., Durrheim and Painter, D (2006). Research in practice. Applied methods for the Social Sciences. Cape Town: Juta and Company.

Blum, K. (2017). Introducing Precision addiction management of reward deficiency syndrome. www.ncbi.nlm.nih.gov Accessed on $12^{\text {th }}$ February 2021.

Chidarikire, M. (2019). Infusion of marginalized voices in peer counselling strategy to alleviate drug abuse in rural learning ecology: Need analysis. International Journal of Research and Innovation in Social Science, III(II), 287-293.

Chikoko V. (2013). Drug problems in schools. Harare: University of Zimbabwe.

Creswell, J.W. (2010). Qualitative inquiry and research design: Choosing among five traditions. Thousand Oaks, CA: Sage.

Creswell, J.W. (2009). Research design. Qualitative, quantitative and mixed methods approaches. ( $5^{\text {th }}$ ed.). London: Sage.

Cooper, R.G. (2009). Alcohol and tobacco abuse in Zimbabwe adolescents. Journal of PreClinical and Clinical Research, 3(2), 89-123.

The Daily Nation, 2012. Causes and problems associated with drug abuse in schools. www.dailynations.org. Accessed $12^{\text {th }}$ February 2021.
Dlamini, P.G. and Makondo, D. (2017). The prevalence of drug abuse among school going teenagers in the Shiselweni region of Swaziland. International Journal of Innovation and Applied Studies, 20(2), 652660.

DuBois, B. and Miley, K.K. (2014). Social work: An empowering profession ( $8^{\text {th }}$ ed.). Boston, MA: Pearson.

Ekpenyong, S.N. (2012). Drug abuse in Nigerian schools: A study of selected secondary institutions in Bayelsa State, South-South, Nigeria. International Journal of Scientific Research in Education, 5(3), 260-268.

Fouché, C.B. and Delport, C.S.L. (2005). In-depth review of literature. In A.S. De Vos, $H$. Strydom, C.B. Fouché and C.S.L. Delport (eds.). Research at grass roots: For the social sciences and human service professions $\left(3^{\text {rd }}\right.$ ed.). Pretoria: Van Schaik.

Geramian, N., Akhavan, S., Gharaat, L., Tehrani, A.M. and Farajzadegan, Z., (2012). Determinants of drug abuse in high school students and their related knowledge and attitude. Journal of the Pakistan Medical Association, 62(3), S62-66.

Gutuza, R.F. and Maploisa, T. (2015). An analysis of the causes of indiscipline amongst secondary school pupils in Nyanja District. Global Journal of Advanced Research, 2(7), 1164-1171.

Hancock, B. Windridge, K and Ockleford, E. (2009). An introduction to qualitative research. Available at: https://www.rdsyh.nihr.ac.uk/wp-content/ uploa ds/ 2013/ 05/5_In troduction-toqualitative-research2009.pdf. (Accessed 05/03/21).

Jakaza, T. N., Nyoni, C. and Muzingili, T. (2018). Emerging dynamics of substance abuse among street children in Zimbabwe: A case of Harare Central Business District. African Journal of Social Work, 8(2), 63-70.

Jiloha, R.C. (2009). Social and cultural aspects of drug abuse in adolescents. Delhi Psychiatry Journal 12(2), 167-175.

Joubert, R. and Serakwane, J. (2009). Establishing discipline in the contemporary classroom. Journal of Educational Studies, 8 (1), 25-137. 
Kirru, N. (2014). Determinants of drug abuse in high school students and their related knowledge and attitude. Journal of education and practice, 6(28), 108-112.

Kombo, D. K. (2005). Sociology of education. Nairobi: Ad Print Publishers.

Ngesu, L.M., Ndiku, J. and Masese, A. (2008). Drug dependence and abuse in Kenyan secondary schools: strategies for intervention. Educational Research and Review, 3 (10), 304-308.

Makanjuola, A., Abiodun, O. and Sajo, S. (2014). Alcohol and psychoactive substance use among medical students of the University of Ilorin, Nigeria. European Scientific Journal, 10(8), 69-83.

Maithya, R., Muola, J.M. and Mwinzi, D. (2013). Motivational factors for substance abuse among secondary school and university students in Kenya: The way forward. International Journal of Asian Social Science, 2 (9), 1548-1563.

Manguvo A., Whitney, S.D. and Chareka, O. (2011). The crisis of student misbehavior in Zimbabwean public schools: Teachers' perceptions on impact of macro socioeconomic challenges. International Journal of Education Administration and Policy Studies, 2(4), 40-44.

Merton, R. and Nisbert, M. R. (2016), Drugs availability and promotion interests cause learners to abuse drugs. https://cambridge.rt.org. Accessed $11^{\text {th }}$ February 2021.

Maseko, M.M., Ngwenya, F. and Maunganidze, L. (2014). Substance Use Among Adolescence in Gweru, Zimbabwe: Perceived Predictive and Protective Factors. The Dyke Journal, 3 (2), 10-45.

Masese, A., Nasongo W. J. and Ngesu, L. (2012). The extent and panacea for drug abuse and indiscipline in Kenyan schools. Asian Journal of Medical Sciences, 4(1), 29-36.

Mathews, S. and Benvenuti, P. (2014). Violence against children in South Africa: Developing a prevention agenda. South African Child Gauge, 1 (2), 26-34.
Mestry, R. and Khumalo, J. (2012). Governing bodies and learner discipline: Managing rural schools. South African Journal of Education, 3(2), 97-110.

Mhizha, S. (2010). The self-image of adolescent street children in Harare, Unpublished M.PHIL Thesis, Department of Psychology, University of Zimbabwe, Harare.

Midigo, V. 2012. Emerging dynamics of substance abuse among rural learners: $A$ case of Shamva secondary schools. African Journal of Social Work, 8(2), 63-70.

Mugabe, M.J. and Maposa, A.D. (2013). Methods of curbing learner misconduct in Zimbabwean secondary schools. International Journal on New Trends in Education and Their Implications, 4(4), 111-122.

Mutsvanga, T. (2011). Alcohol, drug abuse rampant. The Mail, Issue 021 - Saturday 7 May: 3.

Muwanzi, J. and Mafumbate, R. (2018). The nature and effects of substance abuse among adolescents: A case of Mabelreign, Harare, Zimbabwe. International Journal of Science and Research, 7(8), 539-546.

Ndirangu, J.M. (2010). Strategies used by secondary schools to mitigate drug abuse. http://irs.ceua.edu Accessed $3^{\text {rd }}$ March 2021.

Olley, B.O. (2008). Child sexual abuse, harmful alcohol use and age as determinants of sexual risk behaviours among freshmen in a Nigerian University. African Journal of Reproductive Health, 12(2), 75-88.

Oliha, J.A. (2014). Adolescent and drug abuse in tertiary institution implication for counselling.European Centre for Research Training and Development. International Journal of Scientific Research in Education, 6(2), 100-116.

Oketch, D.P. (1997). Pull and push factors for substance abuse among secondary school and university students in Kenya: The way forward. International Journal of Asian Social Science, 2 (9), 1548-1563.

Olugbenga-Bello, A. I., Adebimpe, W. O., Abodunrin, O. L., (2009). Sexual risk behaviour Among in-school adolescents in public secondary schools in a southwestern city in Nigeria, 
International Journal of Health Research, 2 (3), $243-251$.

Omage, E. I. (2005). The incidence of drug abuse among young adults in Oredo Local Government Area of Edo State. Department of Adult and Non Formal Education University of Benin Unpublished Case Studies.

Osman, T., Victor, C., Abdulmoneim, A., Mohammed, H., Abdalla, F., Ahmed, A., Ali, E. and Mohammed, W. (2016). Epidemiology of substance use among university students in Sudan. Journal of Addiction, 1(3),1-8.

Owo, O.I. (2012). Alcohol and other drugs: Prevalence risk factor and the effects on academic performance of high school students in the Mokgalakwena Municipality. South Africa: University of Limpopo.

Pelzer, B. (2009). Consequence of Media and internet use for online and offline network capital and well being. Journal of Computer - Media Communication , 15 (1), 189-210

Ponton, C. 2009. Adolescent drug abuse a curse in schools. International Journal of Health Research, 2 (3), $243-251$.

Sambo , S. (2008). Understanding guidance and counselling. Zaria: Ahamadu Bellow University Press Limited

Silva, L.V. R, Malbergier, A., Stemliuk, V.A and Andrade, A.G. (2006): Factors associated with drug and alcohol use among university students. Revista de Saúde Pública, 40 (2), 280-288.

Sunday Nation (2008). Drug usage escalates among adolescent learners in secondary schools. https://sundaynation.africa Accessed $8^{\text {th }}$ March 2021

Standard, (2015). Health and International Drug policy. https://www.ncdi.mih.gov. Accessed $8^{\text {th }}$ March 2021.

The Standard Newspaper. (2019). Drug abuse in Zimbabwean schools. https://www.thestan dard.co.zW Accessed $9^{\text {th }}$ February 2021

Tesfaye, G., Derese, A. and Hambisa, M.T. (2014). Substance use and associated factors among University Students in Ethiopia: a CrossSectional Study. Journal of Addiction, 1(4), $1-6$

Thun, M.J. and Luiza da Costa e Silva V (2003). Introduction and overview of global tobacco surveillance. Tobacco Control Country Profiles. Atlanta, GA: American Cancer Society.

UNICEF (2006). HIV and AIDS knowledge, attitudes, practices and behaviour (KAPB) study in Namibia. Windhoek: UNICEF Namibia.

United Nations (1994). World Drug Report- United Nations Office on Drug and Crime. https://www.unodc.org. Accessed $23^{\text {rd }}$ March 2021

Yusuf, F.A. (2010). Factors influencing substance abuse among undergraduate students in Osun State, Nigeria. African Research Review, 4(4), 330-340.

Zosel, H. et al. (2009). African, Americans, issues in prevention and treatment. In: Fisher, G.L and Roget, N.A. (Eds.). Encyclopaedia of substance abuse, prevention, treatment and recovery. Singapore: SAGE Publications. 